\title{
Augusto Roa Bastos: Un paraguayo universal (1917-2005)
}

El 26 de abril de 2005 partió para la eternidad Augusto Roa Bastos, escritor que ha hecho conocer al Paraguay en el mundo a través de su literatura. Tenía 87 años; gran parte de ellos los había pasado en el exilio. Nació en Asunción un 13 de junio de 1917, habiendo transcurrido su niñez en el pueblo de Iturbe (Departamento de Guairá) donde su padre brasileño trabajaba como administrativo en una planta azucarera. Roa Bastos realizó sus estudios en el Colegio de San José (desde 1925) no pudiendo concluir sus estudios secundarios debido al estallido de la Guerra del Chaco contra Bolivia (1932 -1935). En 1930, a pedido de su madre, escribe La Carcajada para recaudar fondos para los ex-combatientes de la revolución de 1928. Ese es su primer paso en las letras. En 1933 empieza a trabajar en un banco y colabora en el diario El País de Asunción. En 1934 el joven Augusto se alista como enfermero voluntario, lo cual le impidió poseer una formación académica en letras, pero pudo comprobar la atrocidad de esa guerra que luego le sirvió de material para sus obras, en especial para Hijo de hombre, una de sus obras emblemáticas.

$\mathrm{Al}$ volver de la guerra sigue trabajando como empleado bancario y periodista para el diario El Pais (1935), en donde llega a ser jefe de Redacción. Más tarde hace periodismo radiofónico. Durante la Segunda Guerra Mundial parte a Europa y Africa como corresponsal de guerra. Como poeta perteneció a la Generación del 40 llamada Nido de la Alegría (en Guaraní Vy'a Raity) cuyos principales miembros eran los poetas Josefina Plá, Herib Campos Cervera, Oscar Ferreiro, Elvio Romero, entre otros. Paralelamente a su labor poética, Roa escribió obras dramáticas: La residenta y El niño del rocio ambas en 1942. Ese mismo año recibe una mención en el concurso del Ateneo Paraguayo por su novela Fulgencia Miranda. Acotemos que las dos piezas dramáticas probablemente fueron escritas para el concurso teatral de esa misma institución cultural. En 1946 la compañía teatral del Ateneo Paraguayo le estrena Cuando amanece el día (con dirección del director español Fernando Oca del Valle) obra que trata sobre el nazismo en boga en esa época.

En 1947 se ve obligado a partir a su primer exilio: Argentina. En ese país continuó su labor como periodista y comenzó a sistematizar su trabajo como escritor. Por más de diez años durante la década de los 60 , se dedica a escribir guiones para famosas películas argentinas. En 1974 la editorial Siglo XXI publicó Yo el supremo, su obra maestra. La misma no es una mera 
biografia del dictador José Gaspar Rodríguez de Francia (1814-1849) sino un análisis profundo del poder.

Otra dictadura argentina le obliga a refugiarse en Francia en 1978 donde enseña Literatura y Guaraní en la Universidad de Toulouse le Mirail. En 1982 el dictador Stroessner lo declara persona non grata, le retira su pasaporte y lo expulsa del país. Logra, sin embargo, obtener la ciudadanía española en 1983. En 1985 Francia le otorga la ciudadanía francesa. En la mayoría de sus relatos Roa escribe sobre problemas socio-políticos de su tierra. En 1985 escribe su propia adaptación teatral de Yo el supremo. La misma fue llevada a escena en una versión de Gloria Muñoz en 1991 con rotundo éxito. El primer gobierno democrático le condecora con la Orden Nacional al Mérito del Paraguay (1992); además gana el Premio Nacional de Literatura en 1996. Al obtener éste, decide volver definitivamente a su país. Roa es quien lanza por primera vez la idea de la creación de un Teatro Nacional Popular, sueño aún no realizado.

En enero de 1998 se termina la edición del documental de 90 minutos El portón de los sueños (bajo la dirección del cineasta paraguayo Hugo Gamarra) donde Roa relata su vuelta del exilio y emprende un viaje geográfico y a la vez onírico a Iturbe, su pueblo de infancia. En mayo del 1998 el teatro Arlequín estrena su drama La tierra sin mal bajo la dirección de José Luis Ardissone. Un hecho curioso: Roa a pesar de haber escrito pocos textos dramáticos, su vida literaria empezó escribiendo teatro y acabó su vida haciendo lo mismo. A partir del nuevo milenio, Roa ya prácticamente no escribe más. La Universidad del Norte de Asunción le otorga el cargo de Profesor de Honor en el área de Letras y además Decano en la Maestría de Letras.

Augusto Roa Bastos es el referente más importante en la literatura paraguaya del siglo pasado. Su obra evoluciona desde el realismo social en el cual denuncia la violencia, el abuso del poder por parte de los poderosos y las injusticias sociales, hasta el realismo mágico con sus elementos míticos, raíces de la cultura de su pueblo. Su obra dramática es bastante ecléctica en sus temas. Dramaturgo, poeta, cuentista, periodista, ensayista, novelista, relator de cuentos infantiles, guionista cinematográfico... eso fue el gran Augusto Roa Bastos, ese campesino paraguayo, como él se autocalificaba, que llevó su literatura a la cúspide de la excelencia.

Victor Bogado Jr.

Asunción (julio 2005) 